\title{
Malassezia Species Associated Seborrheic Dermatitis and Its Comparison between HIV Positive and Negative Patients
}

\author{
Harshita Hemant Sisodiya ${ }^{1}$, Nayana Avinash Ingole ${ }^{2}$, Shashir Wanjare ${ }^{3}$, \\ Uday Khopkar ${ }^{4}$, Preeti Mehta ${ }^{5}$ \\ ${ }^{1}$ Assistant Professor Microbiology, Topiwala National Medical College \& BYL Nair Ch Hospital, Mumbai \\ ${ }^{2}$ Professor (Addl) Microbiology, Topiwala National Medical College \& BYL Nair Ch Hospital, Mumbai \\ ${ }^{3}$ Professor (Addl) Microbiology, Seth GS Medical College \& KEM Hospital, Mumbai \\ ${ }^{4}$ Ex Professor \& Head, Dermatology, Seth GSMC \& KEM Hospital, Mumbai \\ ${ }^{5}$ Ex Professor \& Head Microbiology, Seth GS Medical College \& KEM Hospital, Mumbai
}

Corresponding Author: Nayana Ingole

\begin{abstract}
Introduction: Malassezia yeasts are lipophilic organisms causing certain skin diseases. Seborrheic dermatitis (SD) is the second most common skin infection caused by Malassezia as well as in HIV/AIDS.

Aim: To determine the frequency of association of Malassezia species in HIV infected and HIV noninfected patients with Seborrheic dermatitis.

Materials and Methods: The prevalence of Seborrheic dermatitis is 5\% in the general population. Hence a sample size of 80 was derived, 40 each of HIV seropositive and HIV seronegative adult patients clinically suspected of having Seborrheic Dermatitis. Specimens were collected by scraping and cellophane tape for $\mathrm{KOH}$ and Chicago Sky Blue (CSB) stain, and were cultured on Sabouraud's dextrose agar. Data were analysed using SPSS version 16.0. $\mathrm{P} \leq 0.05$ was considered as significant.

Results: Majority of the patients i.e. 46 (57.5\%) out of 80 were in the age group of 18-30 years with male preponderance. All HIV positive patients with SD had scaly, greasy, itchy, hypo-pigmented and erythematous lesions, \& neck (23) and groin (20) were commonest sites. In 39 HIV positive and 22 HIV negative patients, $>2$ sites were involved. Majority of the HIV negative patients with SD had scaly (40), itchy (24) and hypo-pigmented lesions (27) \& dandruff, and scalp (24) \& neck (18) were commonest sites. $(\mathrm{P}<0.05)$. Twenty HIV positive patients had CD4 count ranging from 200-350 cells $/ \mathrm{mm}^{3}$. Malassezia was detected in 38 and 34 HIV positive \& negative patients respectively in laboratory diagnosis.
\end{abstract}

Conclusion: Seborrheic Dermatitis has severe presentation at multiple sites in HIV positive patients as compared to HIV negative patients.

Key Words: Malassezia, Seborrheic dermatitis, HIV positive, HIV negative

\section{INTRODUCTION}

Malassezia yeasts are lipophilic organisms and have been members of normal human cutaneous flora as well as agents of certain skin diseases. Malassezia genus is classified in the order Malasseziales among the Exobasidiomycetes. It is associated with mild, frequently causing recurrent cutaneous infections and also has been associated with skin and deep invasive infections in immunocompromised patients. ${ }^{(1-2)}$

Seborrheic dermatitis (SD) is the second most common infection associated with Malassezia which is a common chronic inflammatory superficial eczematous 
dermatitis, either sub-acute or chronic, characterized by erythematous plaques with dry or oily scales. ${ }^{(3-4)}$

Seborrheic dermatitis affects 3 to $5 \%$ of the global population affecting males more than females. ${ }^{(2)}$ It is seen over areas rich in sebaceous glands, namely the scalp, face, chest, back and flexural areas. ${ }^{(5)} \mathrm{A}$ milder variant is dandruff, which is manifested by dry, flaking scales on the scalp. ${ }^{(4)}$

The exact pathogenesis of adult Seborrheic dermatitis is not known. A combination of hormone levels, weakened immune system, lack of certain nutrients, or nervous system problems may predispose to this infection ${ }^{(6)}$

Seborrheic dermatitis is most common skin infection in HIV/AIDS and its reported prevalence ranges between 20 and $40 \%$ in HIV-1-seropositive patients and between 40 and $80 \%$ in those with AIDS. ${ }^{(7)}$ Its incidence and severity are closely related to the stage of HIV infection and inversely correlate with the absolute CD4 helper T cell counts. ${ }^{(5)}$ Seborrheic dermatitis is more severe and more resistant to therapy in HIV/AIDS patients. ${ }^{(7)}$

The diagnosis of Seborrheic dermatitis is often done clinically. Early diagnosis can be done by microscopy \& culture. Samples are usually collected by direct scraping of skin. The mycological study is most commonly done by potassium hydroxide $(\mathrm{KOH})$ mount and culture. ${ }^{(8)}$

This study aimed to determine the frequency of association of Malassezia species in HIV positive and HIV negative patients with Seborrheic dermatitis.

\section{MATERIALS AND METHOD}

A cross-sectional study was carried out at a tertiary care center over a period of 1 year. Institutional and ethical approvals were obtained. Given a prevalence of seborrheic dermatitis of $5 \%$ in the general population (1) and $40 \%$ in HIV positive patients ${ }^{(7)}$, and taking a confidence level of $95 \%$ and power of $80 \%$, a sample size of 80 was derived for this study, forty each of
HIV seropositive and HIV seronegative patients.

Eighty consecutive adult patients (age $>18$ years) clinically suspected of having Seborrheic dermatitis and presenting to the dermatology clinic during the study period were considered for enrolment. Clinical diagnosis was based on the presence of scaly, greasy lesions. Only those patients whose HIV antibody testing was done in the previous three months were enrolled if willing.

Patients who had been treated with oral or topical antifungal agents in the past one month were excluded. Specimens were collected by scraping and cellophane tape, one each for $\mathrm{KOH}$ mount, $\mathrm{KOH}$ and $\mathrm{CSB}$ mount, and were cultured on Sabouraud's dextrose agar (SDA) with chloramphenicol and gentamicin overlaid with sterile olive oil on tubes and plates of SDA respectively. (Figure 1\& 2)

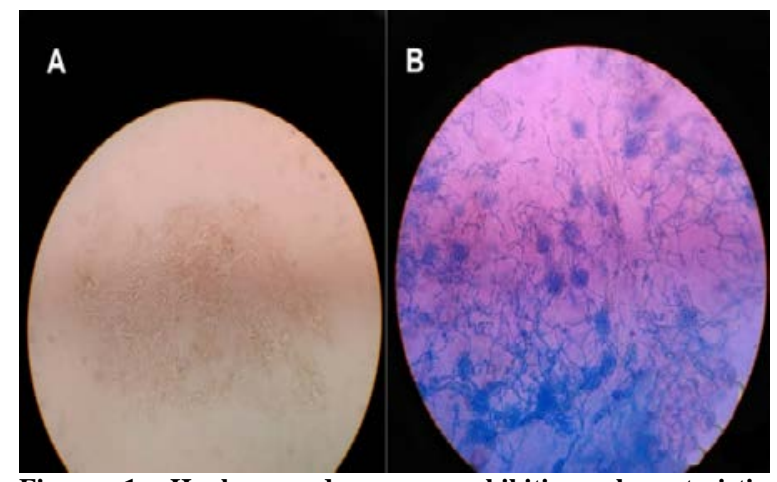

Figure 1. Hyphae and spores exhibiting characteristic appearance of 'Spaghetti and Meatball' appearance in A. KOH mount \& B. CSB stain:

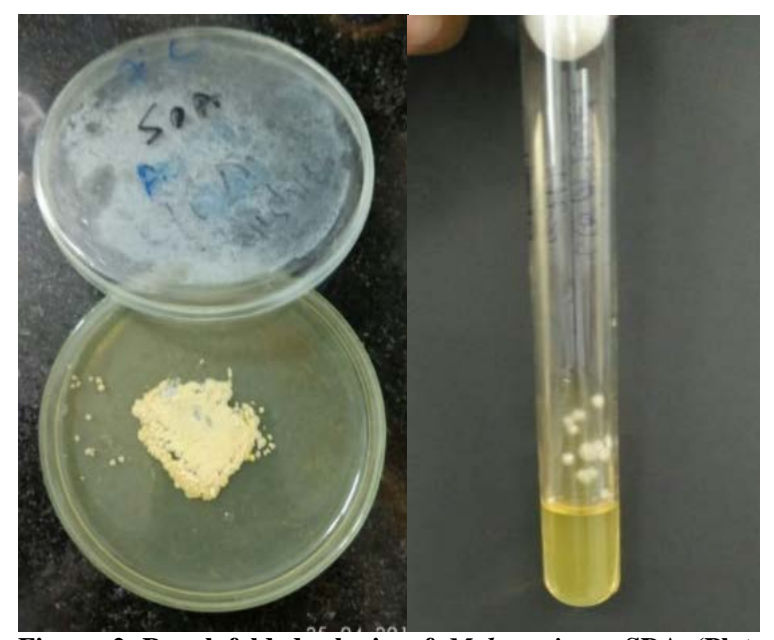

Figure 2: Rough folded colonies of Malassezia on SDA (Plate and Tube): 

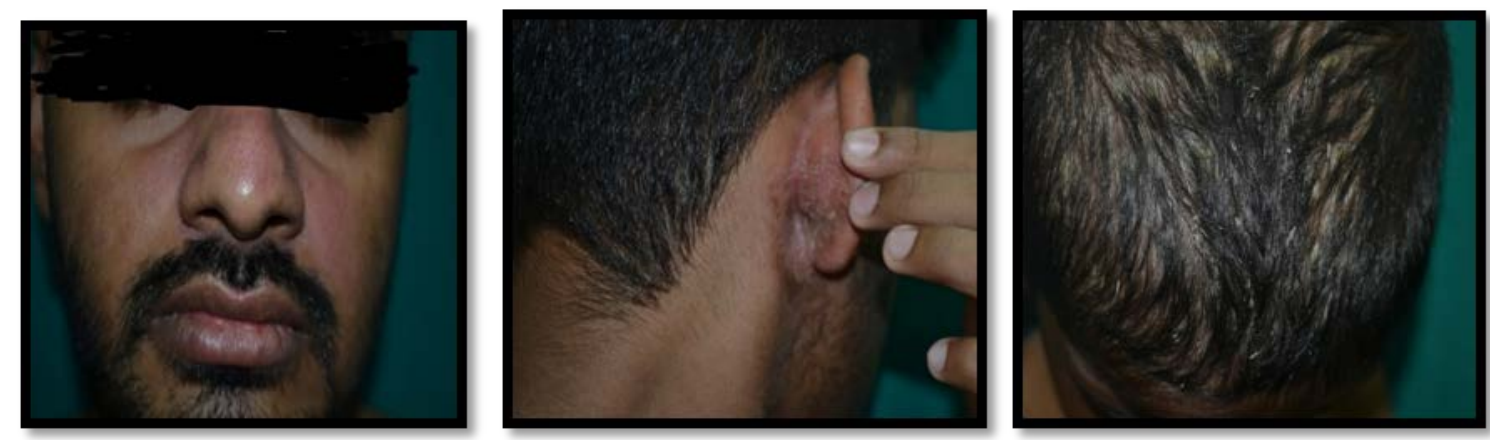

Figure 3. Erythematous lesion on face, hypo pigmented scaly lesion affecting the scalp line and dandruff in Seborrheic Dermatitis patient:

\section{STATISTICAL ANALYSIS}

Data were analyzed using SPSS version 16.0. Descriptive statistics mean, median, minimum, maximum, and percentages were calculated to describe the demographic data. The categorical variables were compared using Pearson's Chi-square test \& McNemar test when appropriate. P value $\leq 0.05$ was considered as significant.

\section{RESULT}

Table 1: Age distribution:

\begin{tabular}{|l|l|l|l|}
\hline \multirow{2}{*}{ Age } & \multicolumn{2}{|l|}{ HIV status } & \multirow{2}{*}{ Total (\%) } \\
\cline { 2 - 3 } & Positive (\%) & Negative (\%) & \\
\hline 18-30 years & $18(39.1 \%)$ & $28(60.9 \%)$ & $46(57.5 \%)$ \\
\hline $30-40$ years & $13(61.9 \%)$ & $8(38.1 \%)$ & $21(26.25 \%)$ \\
\hline$>40$ years & $9(69.2 \%)$ & $4(30.8 \%)$ & $13(16.25 \%)$ \\
\hline Total & 40 & 40 & 80 \\
\hline
\end{tabular}

Majority of the patients i.e. 46 $(57.5 \%)$ out of 80 were in the age group of 18-30 years. Eighteen (39.1\%) HIV positive SD patients and 28 (60.9\%) HIV negative SD patients were less than 30 years of age and there was no statistically significant difference between these two groups. ( $\mathrm{P}=0.068)$

Table 2: Gender distribution:

\begin{tabular}{|c|c|c|c|}
\hline \multirow[t]{2}{*}{ Sex } & \multicolumn{2}{|l|}{ HIV status } & \multirow{2}{*}{ Total (\%) } \\
\hline & Positive (\%) & Negative (\%) & \\
\hline Female & $16(47.1 \%)$ & $18(52.9 \%)$ & 34 (42.5\%) \\
\hline Male & $24(52.2 \%)$ & $22(47.8 \%)$ & $46(57.5 \%)$ \\
\hline Total & 40 & 40 & 80 \\
\hline
\end{tabular}

Male to female ratio was 1.35:1 with a slight male preponderance. However, there was no statistically significant difference between both sexes in HIV positive and negative patients. $(\mathrm{P}=0.821)$

Table 3: Clinical presentation:

\begin{tabular}{|l|l|l|l|l|l|}
\hline \multirow{2}{*}{} & HIV status & \multirow{2}{*}{ Total } & P value & Significance \\
\cline { 2 - 4 } & Positive & Negative & & & \\
\hline Scaly lesions & 40 & 40 & 80 & No stats & No stats as scale is constant \\
\hline Greasy lesions & 40 & 10 & 50 & 0.000 & Significant \\
\hline Itchy lesions & 40 & 24 & 64 & 0.000 & Significant \\
\hline Hypopigmented patch & 40 & 27 & 67 & 0.000 & Significant \\
\hline Hyperpigmented patch & 0 & 5 & 5 & 0.055 & Not Significant \\
\hline Erythematous rash & 40 & 8 & 48 & 0.000 & Significant \\
\hline Dandruff & 0 & 8 & 8 & 0.005 & Significant \\
\hline
\end{tabular}

All HIV positive patients with SD had scaly, greasy, itchy, hypo-pigmented and erythematous lesions. Dandruff was not seen in HIV positive patients. All HIV positive patients had multiple type of lesions.

Majority of the HIV negative patients with SD had scaly (40), itchy (24) and hypo-pigmented lesions (27) \& dandruff in 8 patients.

The difference between the proportion of itchy, greasy, hypo- pigmented, erythematous lesions, and dandruff between HIV Positive and Negative groups, was statistically significant. $(\mathrm{P}<0.05)$

The most common sites affected in HIV positive SD patients were neck (23) and groin (20), followed by back (16), face (14) and chest (14) and in HIV negative SD patients was scalp (24), followed by neck (18), back (13), forehead (11) and nose (10).

The difference between the proportion of Scalp, axilla, and groin 
involvement between HIV positive and negative patients, was statistically significant. $(\mathrm{P}<0.05)$

Table 4: Sites involved:

\begin{tabular}{|l|l|l|l|l|}
\hline Site & $\begin{array}{l}\text { HIV } \\
\text { positive }\end{array}$ & $\begin{array}{l}\text { HIV } \\
\text { negative }\end{array}$ & $\begin{array}{l}\text { P } \\
\text { value }\end{array}$ & Significance \\
\hline Scalp & 14 & 24 & 0.043 & Significant \\
\hline Nose & 4 & 10 & 0.139 & Not Significant \\
\hline Face & 14 & 3 & 0.005 & Not Significant \\
\hline Forehead & 4 & 11 & 0.083 & Not Significant \\
\hline Neck & 23 & 18 & 0.371 & Not Significant \\
\hline Chest & 14 & 6 & 0.069 & Not Significant \\
\hline Back & 16 & 13 & 0.642 & Not Significant \\
\hline Extremeties & 15 & 4 & 0.154 & Not Significant \\
\hline Axilla & 7 & 0 & 0.012 & Significant \\
\hline Groin & 20 & 0 & 0.000 & Significant \\
\hline
\end{tabular}

Table 5: Number of sites involved:

\begin{tabular}{|l|l|l|l|}
\hline \multirow{2}{*}{ Number of sites } & \multicolumn{2}{|l|}{ HIV status } & \multirow{2}{*}{ Total } \\
\cline { 2 - 3 } & Positive & Negative & \\
\hline 1 & 0 & 3 & 3 \\
\hline 2 & 1 & 15 & 16 \\
\hline$>2$ & 39 & 22 & 61 \\
\hline Total & 40 & 40 & 80 \\
\hline
\end{tabular}

In 39 HIV positive and in $22 \mathrm{HIV}$ negative patients, $>2$ sites were involved and the difference was statistically significant. $(\mathrm{P}=0.000)$

\section{CD4 count in HIV positive SD patients:}

In HIV positive patients, 20 patients had CD4 count ranging from 200-350 cells $/ \mathrm{mm}^{3}$ \& mean CD4 cell count was 348.72. ( \pm 101.944$)$ Two patients had count less than 200 cells $/ \mathrm{mm}^{3}, 15$ patients had count ranging from 350 to 500 cells $/ \mathrm{mm}^{3}$ \& 3 patients had count more than 500 cells $/ \mathrm{mm}^{3}$. However, no significant association was found between clinical presentation \& sites involved and CD4 count.

\section{Laboratory Diagnosis:}

Using scraping/cellotape with $\mathrm{KOH}$ mount/Chicago Sky Blue 6B stain, Malassezia was detected in 38 and 34 HIV positive $\&$ negative patients respectively by any of the collection/staining methods used and the difference was not statistically significant.

\section{DISCUSSION}

Seborrhoeic dermatitis (SD) is a common, relapsing dermatitis that is characterized by erythematous patches and superficial scaling affecting sebaceous-rich areas - namely the scalp, face, central chest and anogenital areas. ${ }^{(9)}$

Seborrheic dermatitis has two peak prevalence, an infantile self-limited form during the first 3 months of life and an adult form that is chronic. ${ }^{(10)}$ The course of adult SD in affected individuals is variable throughout adulthood, some noting only occasional periods of exacerbation and others experiencing greater chronicity with more frequent recurrences. ${ }^{(9)}$

SD has been reported to be more common in the age group of 30 to 60 years as reported by majority of authors. ${ }^{(11-12)}$ Manapajon Araya et al has reported 41.1 years as a mean age of SD in a study conducted at Bangkok, Thailand. (11) Similarly, in the study conducted by J.Peyri et al, at Barcelona, Spain 43.6 years was the mean age of diagnosis of SD. ${ }^{(12)}$

In present study, only adults were included. The age of the patients ranged from 18 years to 70 years. Majority of the patients i.e. 46 out of 80 were less than 30 years and the mean age was 31.5 years.(Table 1) There was no significant difference in age between HIV positive and HIV negative patients of SD. Similar findings have been reported by Yulien Amado et al. ${ }^{(13)}$

Age-related changes in the extent of colonization and the composition of the Malassezia microbiota are closely associated with age-related changes in sebaceous gland activity and the fatty acid composition of sebum. ${ }^{(14)}$

$\mathrm{SD}$ is a multifactorial skin disease that needs endogenous and exogenous predisposing factors for its development. Various authors have reported a male preponderance. $^{(15-17)}$ R.U Peter et al in Munich, Germany, reported that out of 575 patients, 404 were males and 171 were females. ${ }^{(17)}$ Similarly, Schaub NA et al and Valentina et al have also reported a male preponderance. ${ }^{(15-16)}$ This suggests a significant hormonal influence, mainly of androgens. ${ }^{(9,18)}$ However, few authors have 
also reported a female preponderance. ${ }^{(11,19-}$ 20)

In present study, out of 80 patients, 46 patients were males and 34 were females with a Male to female ratio of 1.35:1. (Table 2) There was no significant difference in both the sexes $(\mathrm{P}=0.411)$. Our observation is consistent with studies of Yulien et al and Valentina et al. ${ }^{(13,16)}$

Gender might not be the significant factor in the development of SD. But this can be more associated with the possible opportunistic activity of Malassezia spp., which can use their lipid machinery from human sebum, for growth, releasing fatty acids, and thus generating epidermis damage, which may be related to the development of SD. ${ }^{(13)}$

Adult SD is reported to involve one or more sites which includes scalp, eyebrows, forehead, nasal alar creases, chest and genital region. ${ }^{(12)} \mathrm{SD}$ tends to occur early in the course of HIV positive cases, and is usually more severe and difficult to diagnose and treat than in the general population. (21-22) Most of the authors like, Manapajon Araya et al, J Peyri et al, Barbara M Mathews et al have reported face and scalp as the most common sites of SD followed by thorax, nasolabial folds and eyebrows. ${ }^{(11-12,13)}$

Manapajon Araya et al reported pruritus as the most common complaint while study J. Peyri et al, reported scales and erythema as the most common complaint. (11-12) Seborrheic dermatitis in HIV positive patients is explosive, inflammatory, and severe and is recalcitrant to treatment.

Clinically, as showed in Table 3 and Table 4, there was extensive involvement of sites in HIV positive SD patients beyond typical seborrheic areas, including the extremities, groin, axillae and scalp as compared to SD in HIV negative patients. It was also noted that there was multiple sites involvement in HIV positive SD patients as shown in Table 5 compared to HIV negative SD patients. In HIV negative SD patients, scalp was the most common site with dandruff as the most common complaint. (Figure 3) HIV positive patients with SD had scaly, greasy, itchy, hypo-pigmented and erythematous lesions. (Table 3 \& 4) This is consistent with the findings of other reports. ${ }^{(21-23)}$

Several studies revealed a significant association between disease progression, immunologic status and manifestation and severity of SD. ${ }^{(24-26)}$ A defect in immune response (specific or not) may facilitate fungal survival in the skin. Bergbrant et al. has reported that in AIDS patients who often show abnormal T-cell function, the function of a different Malassezia-compliant method that does not require $\mathrm{T}$-cell function is suppressed and may be the explanation for the inflammatory response. ${ }^{(22)}$ Parry and Sharpe suggested that SD is not caused by altered immune responses to Malassezia yeast and proposed toxic production or lipase activity as possible mechanisms.. ${ }^{(27)}$ Other researchers have shown that the lipophilic yeast is able to activate the alternative pathway of complement. All of the above processes can cause indirect skin inflammation. In short, impairment in the immune response (direct or not) may facilitate the survival of the fungus on the skin. ${ }^{(2,22,28)}$ HIV/AIDS affects the response of keratinocytes to stress signals. It also has detrimental effects on Langerhans cells and their cross-talk with CD-4 memory lymphocytes resulting in virus replication and destruction of both subsets of immune cells, thus destabilizing the skin immune system. ${ }^{(29)}$ The increase in prevalence of SD in people with AIDS likely correlates with $\mathrm{T}$ cell lymphopenia, affecting counts of CD4+ cells involved in immune surveillance. ${ }^{(9)}$

In the study conducted by Yitayih et al in Gondar, out of 292 HIV positive SD cases, 245 patients had CD4 count above 200 cells/mm3 and 47 patients had less than 200cells/mm3. ${ }^{(30)}$ Nnoruka et al, in a study from Nigeria in the year 2007 found that SD was the second most common mucocutaneous disorder with a mean CD4 cell count of $453.8 \pm 153$ cells $/ \mathrm{mm} 3$. ${ }^{(31)}$ CD4 count was between 200 to 500 
cells/mm3 in 69 patients out of 99 . The high mean CD4+ cell count and high mean total lymphocyte count observed in these disorders can be explained by the fact that both mucocutaneous disorders occur early in HIV infection, as similarly reported elsewhere. ${ }^{(31)}$ In the studies carried out by, Manapajon Araya et al,(11) Yitayih et al, Nnoruka EN et al, R Lifson et al, Amy K Forrestel et al, mean CD4 count ranged from 200 to 400 cells/mm3. ${ }^{(11,30-33)}$ Goh BK et al found that CD4 less than 200 cells/mm3 are prone to skin diseases. ${ }^{(34)}$ In the study done at Basel, Switzerland in 1998, by Schaub N et al found that neither the initial CD4 $\mathrm{T}$ cell count nor antiretroviral treatment is of any significance in the development of SD. ${ }^{(9)}$ Similar findings were seen in the current study which could be due to the higher values of CD4 count and history of ART in almost all patients. (38 patients) However, no significant association was found between clinical presentation \& sites involved and CD4 count.

The diagnosis of SD is based on typical clinical picture, positive direct microscopy and culture of the lesion. ${ }^{(9)}$ The disease can be easily diagnosed by an experienced dermatologist, but this should always be confirmed with direct microscopy or culture to demonstrate pseudohyphae and blastoconidia in typical "spaghetti and meatballs" pattern. In this study, samples were collected using scalpel for scraping as well as cellotape from the affected site and were subjected to $\mathrm{KOH}$ mount and Chicago Sky Blue 6B stain. Malassezia was detected in 38 and 34 HIV positive \& negative patients respectively by any of the collection/staining methods used and the difference was not statistically significant.

\section{CONCLUSION}

Seborrheic Dermatitis has an unusual and severe presentation at multiple sites in HIV positive patients as compared to HIV negative Seborrheic Dermatitis.

Acknowledgement: None

\section{Conflict of Interest: None \\ Source of Funding: None}

\section{Ethical Approval: Approved}

\section{REFERENCES}

1. Thayikkannu AB, Kindo AJ, Veeraraghavan M. Malassezia-can it be ignored?. Indian journal of dermatology. $2015 \mathrm{Jul} ; 60(4)$ :3329.

2. Chatzikokkinou P, Sotiropoulos K, Katoulis A, Luzzati R, Trevisan G. Seborrheic dermatitis- an early and common skin manifestation in HIV patients. ACTA Dermatovenerologica Croatica. 2008 Apr 1;16(4):226-30.

3. 3 Hay RJ, Midgley G. Introduction: Malassezia yeasts from a historical perspective. In Malassezia and the skin 2010 (pp. 1-16). Springer, Berlin, Heidelberg; 2010

4. Berk T, Scheinfeld N, Luisa A, Bittencourt S, Nunes AP, Cristina Â, et al. Seborrheic dermatitis. An Bras Dermatol [Internet]. 2011;86(6):1061-74.

5. Valia RG. Etiopathogenesis of seborrheic dermatitis. Indian Journal of Dermatology Venereology And Leprology. 2006 Jul 1;72(4):253.

6. Okokon EO, Verbeek JH, Ruotsalainen JH, Ojo OA, Bakhoya VN. Topical antifungals for seborrhoeic dermatitis. Cochrane Database of Systematic Reviews. 2015(5).

7. Gaitanis G, Magiatis P, Hantschke M, Bassukas ID, Velegraki A. The Malassezia genus in skin and systemic diseases. Clinical microbiology reviews. 2012 Jan;25(1):106-41.

8. Jagdish Chander. Malassezia Infections Textbook Of Medical Mycology. In: 3rd editio. Mehta publishers; 2002. p. 92-102

9. Del Rosso JQ. Adult seborrheic dermatitis: a status report on practical topical management. The Journal of clinical and aesthetic dermatology. 2011 May;4(5):32.

10. Goldsmith L, Katz S, Gilchrest BA, Paller AS, Leffell DJ, Wolff K. Fitzpatrick's Dermatology in General Medicine, Ed. McGraw Hill Medical. 2012;150(4):22.

11. Araya M, Kulthanan K, Jiamton S. Clinical characteristics and quality of life of seborrheic dermatitis patients in a tropical country. Indian journal of dermatology. 2015 Sep;60(5):519. 
Harshita Hemant Sisodiya et.al. Malassezia species associated seborrheic dermatitis and its comparison between HIV positive and negative patients.

12. Peyri J, Lleonart M. Clinical and therapeutic profile and quality of life of patients with seborrheic dermatitis. Actas DermoSifiliográficas (English Edition). 2007 Jan 1;98(7):476-82.

13. Amado Y, Patiño-Uzcátegui A, Cepero de García MC, Tabima J, Motta A, Cárdenas M, Bernal A, Restrepo S, Celis A. Seborrheic dermatitis: predisposing factors and ITS2 secondary structure for Malassezia phylogenic analysis. Medical mycology. 2013 Nov 1;51(8):868-75.

14. Sugita T, Boekhout T, Velegraki A, Guillot J, Hađina S, Cabañes FJ. Epidemiology of Malassezia-related skin diseases. InMalassezia and the Skin 2010 (pp. 65119). Springer, Berlin, Heidelberg.

15. Schaub NA, Drewe J, Sponagel L, Gilli L, Courvoisier S, Gyr N, Rufli T, Battegay M, Itin $\mathrm{P}$. Is there a relation between risk groups or initial CD4 $\mathrm{T}$ cell counts and prevalence of seborrheic dermatitis in HIVinfected patients?. Dermatology. 1999; 198(2): 126-9.

16. Arsenijevic VS, Milobratovic D, Barac AM, Vekic B, Marinkovic J, Kostic VS. A laboratory-based study on patients with Parkinson's disease and seborrheic dermatitis: the presence and density of Malassezia yeasts, their different species and enzymes production. BMC dermatology. 2014 Dec;14(1):1-9.

17. Peter RU, Richarz-Barthauer U. Successful treatment and prophylaxis of scalp seborrhoeic dermatitis and dandruff with 2\% ketoconazole shampoo: results of a multicentre, double-blind, placebo-controlled trial. British Journal of Dermatology. 1995 Mar;132(3):441-5.

18. Dessinioti C, Katsambas A. Seborrheic dermatitis: etiology, risk factors, and treatments: facts and controversies. Clinics in dermatology. $2013 \mathrm{Jul}$ 1;31(4):343-51.

19. Forrestel AK, Kovarik CL, Mosam A, Gupta D, Maurer TA, Micheletti RG. Diffuse HIV-associated seborrheic dermatitis-a case series. International journal of STD \& AIDS. 2016 Dec;27(14): 1342-5.

20. Wondimeneh Y, Ferede G, Yismaw G, Muluye D. Total lymphocyte count as surrogate marker for CD4 cell count in HIV-infected individuals in Gondar University Hospital, Northwest Ethiopia.
AIDS Research and Therapy. 2012 Dec;9(1):1-4.

21. Motswaledi MH, Visser W. The spectrum of $\mathrm{HIV}$-associated infective and inflammatory dermatoses in pigmented skin. Dermatologic clinics. 2014 Apr 1;32(2): 211-25.

22. Huang XJ, Li HY, Chen DX, Wang XC, Li ZC, Wu YS, Zhang T, Gao YQ, Wu H. Clinical analysis of skin lesions in 796 Chinese HIV-positive patients. Acta dermato-venereologica. 2011 Sep 1;91(5): 552-6.

23. Mathes BM, Douglass MC. Seborrheic dermatitis in patients with acquired immunodeficiency syndrome. Journal of the American Academy of Dermatology. 1985 Dec 1;13(6):947-51.

24. Garbe C, Husak R, Orfanos CE. HIVassociated dermatoses and their prevalence in $456 \mathrm{HIV}$-infected patients. Relation to immune status and its importance as a diagnostic marker. Der Hautarzt; Zeitschrift fur Dermatologie, Venerologie, und verwandte Gebiete. 1994 Sep 1;45(9):623-9.

25. Smith KJ, Skelton HG, Yeager J, Ledsky R, McCarthy W, Baxter D, Wagner KF. Cutaneous findings in HIV-1-positive patients: a 42-month prospective study. Journal of the American Academy of Dermatology. 1994 Nov 1;31(5):746-54.

26. Schechtman RC, Midgley G, Hay RJ. HIV disease and Malassezia yeasts: a quantitative study of patients presenting with seborrhoeic dermatitis. British Journal of Dermatology. 1995 Nov;133(5):694-8.

27. Parry ME, Sharpe GR. Seborrhoeic dermatitis is not caused by an altered immune response to Malassezia yeast. The British journal of dermatology. 1998 Aug 1;139(2):254-63.

28. Moehrle M, Dennenmoser B, Schlagenhauff B, Thomma S, Garbe C. High prevalence of seborrhoeic dermatitis on the face and scalp in mountain guides. Dermatology. 2000; 201(2):146-7.

29. Nestle FO, Di Meglio P, Qin JZ, Nickoloff BJ. Skin immune sentinels in health and disease. Nature Reviews Immunology. 2009 Oct;9(10):679-91.

30. Wondimeneh Y, Ferede G, Yismaw G, Muluye D. Total lymphocyte count as surrogate marker for CD4 cell count in HIV-infected individuals in Gondar University Hospital, Northwest Ethiopia. 
Harshita Hemant Sisodiya et.al. Malassezia species associated seborrheic dermatitis and its comparison between HIV positive and negative patients.

AIDS Research and Therapy. 2012 Dec;9(1):1-4.

31. Nnoruka EN, Chukwuka JC, Anisuiba B. Correlation of mucocutaneous manifestations of HIV/AIDS infection with CD4 counts and disease progression. International journal of dermatology. 2007 Nov;46:14-8.

32. Lifson AR, Hessol NA, Buchbinder SP, Holmberg SD. The association of clinical conditions and serologic tests with CD4+ lymphocyte counts in HIV-infected subjects without AIDS. AIDS (London, England). 1991 Oct 1;5(10):1209-15.

33. Forrestel AK, Kovarik CL, Mosam A, Gupta D, Maurer TA, Micheletti RG. Diffuse HIV-associated seborrheic dermatitis- a case series. International journal of STD \& AIDS. 2016 Dec;27(14): 1342-5.

34. Goh BK, Chan RK, Sen P, Theng CT, Tan $\mathrm{HH}, \mathrm{Wu}$ YJ, Paton NI. Spectrum of skin disorders in human immunodeficiency virus-infected patients in Singapore and the relationship to CD4 lymphocyte counts. International journal of dermatology. 2007 Jul;46(7):695-9.

How to cite this article: Sisodiya $\mathrm{HH}$, Ingole NA, Wanjare $\mathrm{S}$ et.al. Malassezia species associated seborrheic dermatitis and its comparison between HIV positive and negative patients. Int J Health Sci Res. 2021; 11(12): 197-204. DOI: https://doi.org/10.52403/ijhsr. 20211226 